\title{
Conference Report - "NURTURE A.R.T. Self" - Adolescent Mental Health and Art Therapy International Conference 2016 (Hong Kong)
}

\section{会议报告: “培育艺术自我” - 未成年人心理健康和艺术治疗 2016香港国际会议}

\author{
Grace WY Chan, Tristan NC Chan, Hoi Lam Tang and \\ Sarah MM Tong \\ Hong Kong Association of Art Therapists
}

\begin{abstract}
Art therapy is becoming a popular topic in the metropolitan city of Hong Kong. The attention it attracts often correlates to the heightened awareness of mental health issues - particularly the rise of adolescent suicide cases and the overwhelmingly high number of young people reportedly affected by both anxiety and depression. As school officials and health care administrators look to different measures to deal with these issues - such as better life education and planning to support the development of teenagers - the general public now wonders if art therapy could be an alternative means of treating and supporting adolescent mental health. In the hope of educating the public about art therapy and promoting its healing power, HKAAT* and CFSC co-hosted the "NURTURE A.R.T. Self" Art Therapy Conference in Hong Kong last year, exploring the scope of practices that art therapy brings to addressing such issues of adolescent mental health. The conference attracted nearly 200 participants and featured over 20 lectures and workshops that were presented by both local and overseas practitioners and scholars. Its aims were to foster an intellectual exchange of research methods and therapy practice insights and to provide an in-depth review of the application of art therapy in a variety of groups - specifically in the treatment of such psychological issues such as self-mutilation, domestic violence and depression.
\end{abstract}

Keywords: Hong Kong art therapy, art psychotherapy, conference, art therapy, hkaat, Hong Kong association of art therapists, nurture self, adolescent, CFSC

\begin{abstract}
摘要
艺术治疗正逐渐在大都市香港成为一个广为人知的话题。大家对艺术治疗的觉知伴随着他 们对心理健康的重视，特别是在这青少年自杀率上升以及铺天盖地的年轻人被诊为焦虑和 抑有陹时期。学校领导和卫生保健管理人员寻找不同方法应对这些事件，比如更好的生活 教育和计划来支持青少年的发展。而广大群众如今则设想 : 艺术治疗也许能成为治疗和保 护青少年心理健康的另一个途径。为了教育广大群众艺术治疗以及它的疗效，去 年，HKAAT和CFSC在香港合办了 “培育艺术自我” 的艺术治疗会议。其目的在于探索艺 术治疗在保护青少年心理健康中起到的帮助。会议吸引了近二百参与者，提供了二十多个 由海内外学者和医生主讲的课程与工作坊。会议的目标在于促进研究方法和治疗实践洞悉
\end{abstract}


间的知识交流，并提供一个怎样用艺术治疗与不同人群工作的细致回顾。会议中主要提到 的接受艺术治疗的人群包括有自残行为、面临家暴和抑有陹有心理问题的人群。

\section{关键词: 香港艺术治疗，艺术心理治疗，研讨会，艺术治疗，香港艺术治疗协会，青年人，基督教家庭} 服务中心

\section{Hong Kong: background and social issues}

In recent years, the positive mental health of the adolescent population has become a topic of increasing concern within the Hong Kong community. Adolescents in Hong Kong experience many forms of challenges. Some stressors originate from cramped home settings and family environments; others develop as a result of challenging social environments - social bullying at school, traumatic personal events and maladaptation to social and academic expectations. In some cases, these stressors appear in teenagers who already possess a predisposition to some kind of mental illness or who have experienced some learning difficulties. In the past academic year, one young student after another has taken their own lives; they have left behind them a great deal of unresolved grief and many unanswered questions. Our society has now begun to question how we can better equip our adolescents with a strong sense of resilience that will allow them to meet and cope with challenges in life. In search of a remedy, the Oscar acceptance speech delivered by Pete Doctor, director of "Inside Out", probably offers some of the best advice for both adolescents and their caregivers:

“Anyone out there who's in junior high, high school, working it out, suffering there are days you're going to feel sad. You're going to feel angry. You're going to feel scared. That's nothing you can choose. But you can make stuff. Make films. Draw. Write. It will make a world of difference."

The power of creativity can make a tremendous difference in human lives - especially for adolescents whose sense of identity, burgeoning relationships, and future prosperity are all still in very early stages of development. Art might not take away any of that pain or all of those difficulties, yet the metaphor of art-making becomes a powerful tool for adolescents. It allows them to find an order in chaos and to gain control over uncertainty. In recent years, the general public in Hong Kong has gradually become aware that art therapy may be a viable and positive resource for supporting adolescents as they learn to cope with different obstacles in their lives.

Over the past few years, with the growth of overseas-trained art therapists returning to serve the Hong Kong community, art therapy has become a more acceptable means of treatment within the mental health community. Paradoxically, however, with more attention being given to those who talk about art therapy, there is a greater sense of confusion and misunderstanding of "what art therapy is" and of how it can be beneficial to our teenagers.

There currently exist some unhealthy perceptions and superstitions about art therapy - namely that it is somehow equal to predictive drawing where art therapists will analyze clients' pictures just as a fortune-teller might do. There are also many non-art therapists providing art therapy training courses to anyone who wishes to learn more 
about art therapy. Some may perceive art therapy simply as providing fun, relaxing recreational activities - activities that can be led by anyone with limited training. Although "art is for all", art therapists often work with vulnerable populations, and doing so without a clear understanding both of the ethics of art therapy and the necessary sensitivity in applying different art approaches may very well create risk for those who wish to seek help for psychological issues.

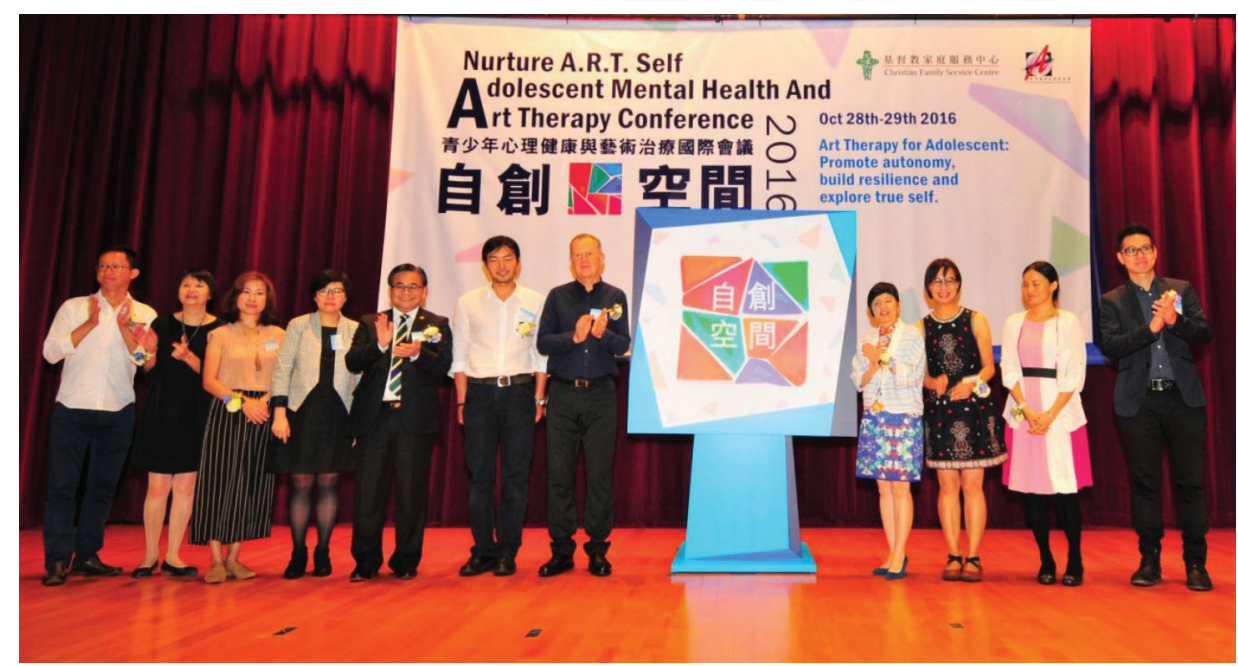

FIGURE 1 | Opening of the "Nurture A.R.T. Self” Conference 2016

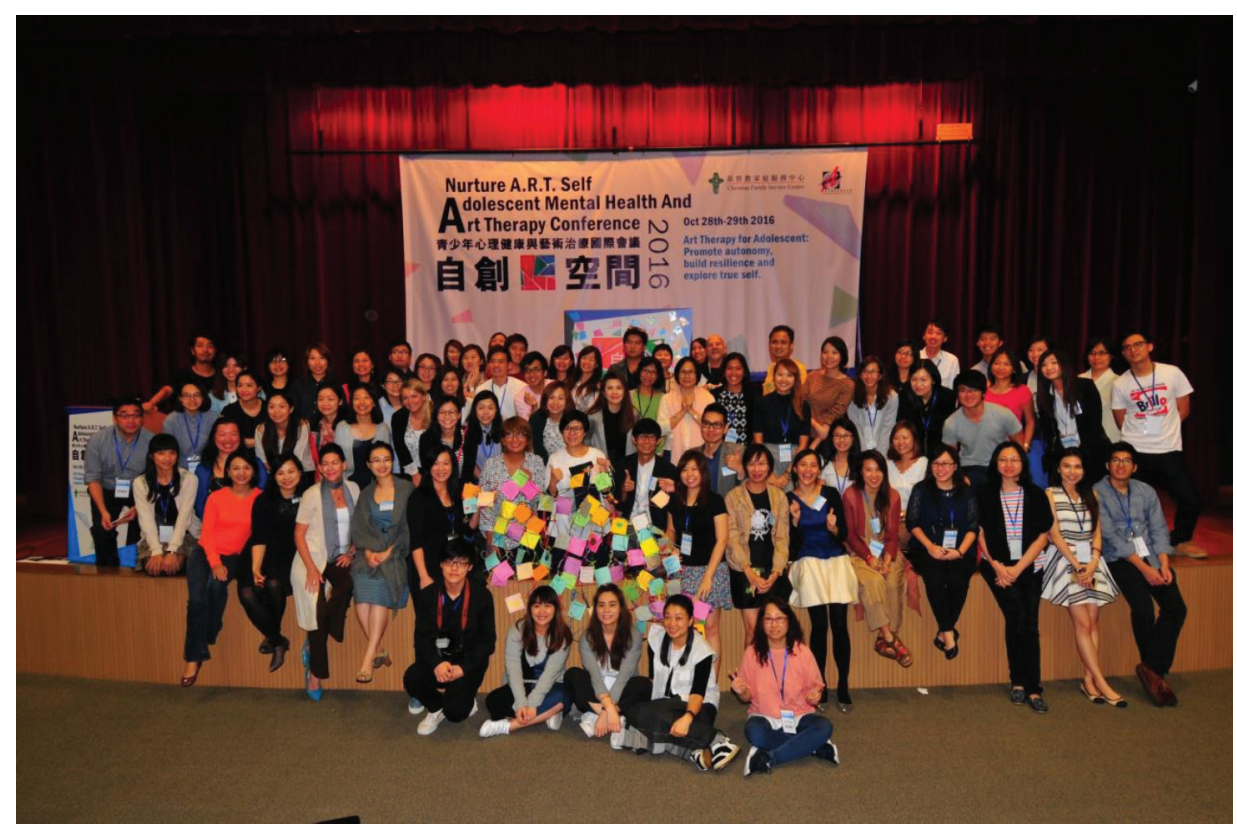

FIGURE 2 | Closing of the "Nurture A.R.T. Self” Conference 2016 


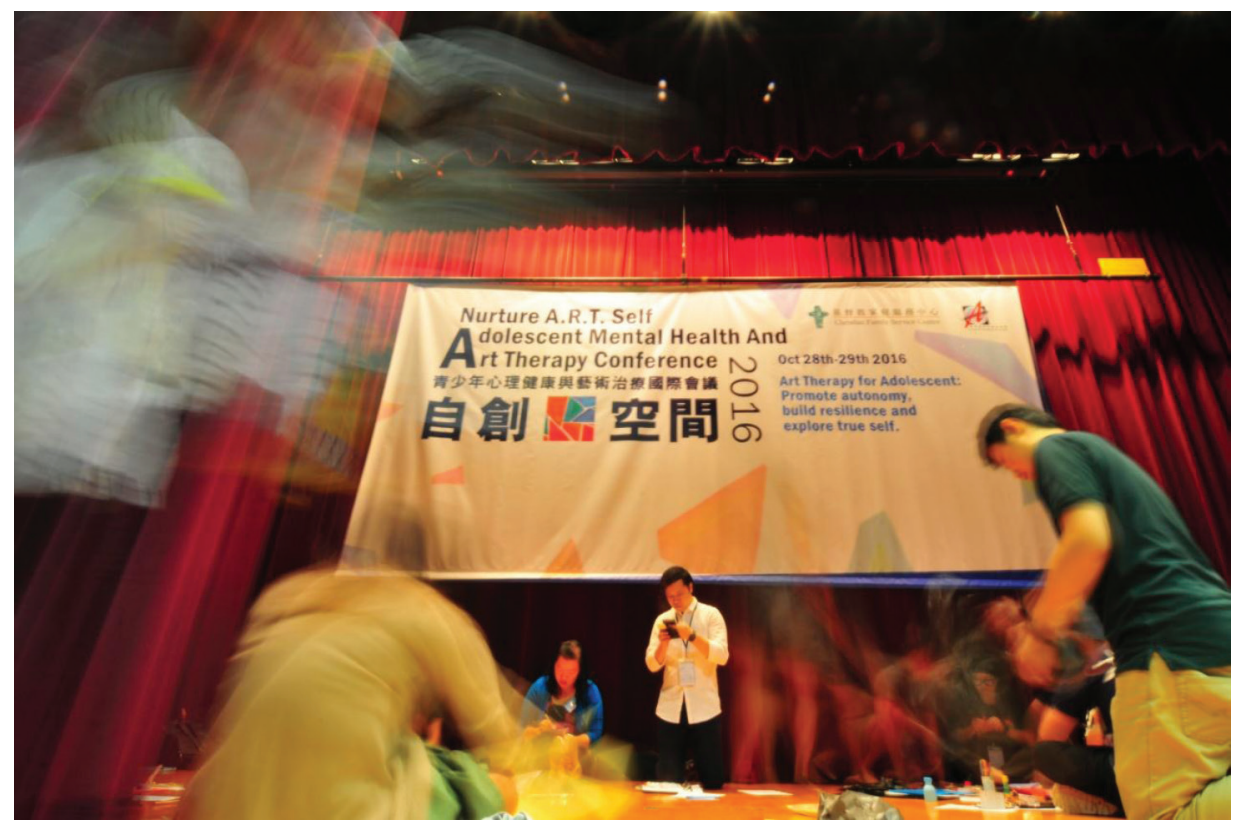

FIGURE 3 | Creating at the Experiential workshop

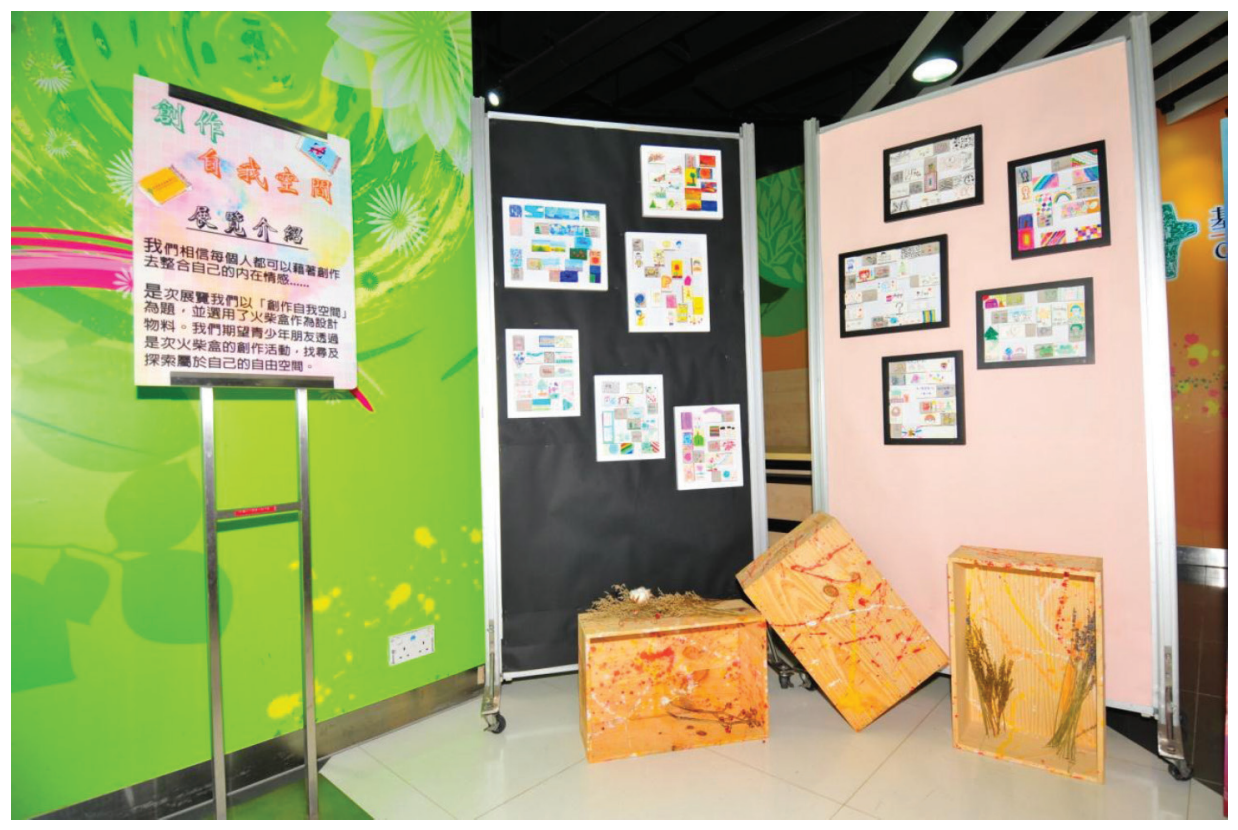

FIGURE 4 | Display of Secondary school students' artwork - Matchboxes 


\section{Gathering experts in the field from East and West}

In order to fully explain the fundamentals of art therapy to the general public - and in response to an increased demand for professional mental health services for teenagers HKAAT was blessed with the opportunity to co-host a conference on Adolescent Mental Health and Art Therapy: "NURTURE A.R.T. Self" with The Christian Family Service Center in October 2016. The primary aim of this conference was to promote art therapy by educating the public in the healing power of art. Participants were able to take a glimpse of the art therapy process itself and to gain a greater understanding of the theories, the ethics and the sensitive application of art in therapy.

For the main conference, two internationally recognized art therapy scholars were the keynote speakers. Dr Neil Springham from the UK, and Dr Ming- Fu WU from Taiwan shared their years of research and clinical experience with us. Ms. Ivy Fung $-\mathrm{a}$ local art therapy pioneer and an art therapy researcher - joined us in the conference; additionally, Joshua Nun (an art historian) and Dr Sophia Law shared their clinical experiences and research findings with our participants.

Dr. Springham discussed the importance of both qualitative and quantitative research in art therapy. The neuroscience theory, attachment theory and social sciences and the research and practice of Mentalization-based treatment could provide practitioners with such tools as would allow them to communicate the effectiveness and benefits of art therapy both to the general public and to people who need the service. Research also helped to confirm and improve the theories of art therapy practice.

Dr. Wu shared his experience of working in New York City during the catastrophic events of 9/11 and explained how art helped to support those teenagers who had experienced this traumatic event. His words illustrated both the therapeutic power of art and the effectiveness of art therapy when used with an adolescent population - despite the diverse cultural backgrounds. Art, we were reminded, was and is a universal language which crosses cultural divides.

Hong Kong Art therapy pioneer Ms. Ivy Fung shared her years of experience in working with adolescents; she shared case studies which showed how her teenage clients were able to find a outlet for their emotions and a means of expressing their feelings and releasing their anger through art making.

Local scholar and art therapist Dr. Joshua Nan shared his research study on clay art therapy undertaken by a number of clients suffering from depression. Even though clay remains a popular medium for use during art therapy sessions, there is very limited research on its therapeutic use and benefits in such an environment. Dr. Nan's research study offered local and international scholars a new perspective and insight into how clay art making, facilitated in a therapeutic group setting, could be beneficial in improving mood, promoting a full expression and integration of self, and motivating social interaction between depressed clients.

Art historian Dr. Sophia Law shared the findings of her research on art as an intervention in serving secondary child victims of family violence. She collaborated with art therapist Sarah Tong in using a child-centered psycho-educational art therapy approach and found that art and creativity could form a beneficial non-verbal platform where child victims of family violence could safely express their repressed emotions. 
In addition to the keynote speeches and the sharing of research and practice from our key speakers, local researchers, art therapy professionals and social workers also shared their research studies outcomes and clinical frontline experiences through both lectures and experiential workshops. Workshop and lecture topics included: art therapy for cancer patients, adolescent body image and self-mutilating behavior, sexual abuse trauma, the use of body-outline experiential and community arts project implementation. Participants had the opportunity (in both group and individual sessions) to produce art works during hands-on experiential sessions. Participants experienced that artmaking can be fun, safe, and a powerful means of self-expression.

During the conference there was an exhibition showcasing artworks created by a number of adolescents who shared their worldview through images created within match-boxes. Participants were able to experience not only the fun side of art making but also came to understand how art therapists could sensitively use art as a means of helping them open a safe door to express their experiences, trauma, worldviews, feelings and thoughts without any fear of being judged.

\section{Challenges and moving forward}

This conference drew the attention of and received feedback from caregivers, the general public and those who care about our future generation. It enabled these groups to come together and created a platform where knowledge could be exchanged and information could be developed on how to make Hong Kong a better place for adolescents by applying the therapeutic uses of art. Participants gained a greater awareness of the concept of art therapy and explored how art could work in a positive way for our adolescents.

This conference also shed light on the cultural-sensitive aspects of art therapy when it is being administered to the Chinese population. While adopting art therapy practice from the West, more research may be needed to strengthen the Chinese/Eastern model in order to address the specific societal needs of the Chinese population.

As evidenced by the responses from the conference, it has come to HKAAT's attention that a growing number of Hong Kong locals are being drawn into the healing power of art therapy. Unfortunately, only limited resources are currently available due to the relatively small art therapy service sector in Hong Kong. HKAAT foresees more collaboration with local social service organizations that will continue to promote art therapy and mental health wellness among our community. This conference was one step toward more collaboration; our hope now is that by educating and promoting art therapy to the public, more people will benefit from its quality and will gain a deeper understanding of how art therapy works.

\section{About the Authors}

Grace WY Chan, ATR-BC, Treasurer of the Hong Kong Association of Art Therapists. Tristan NC Chan, RAP, Conference Co-chair, Vice-president of the Hong Kong Association of Art Therapists. 
Hoi Lam Tang, ATR, Secretary of the Hong Kong Association of Art Therapists.

Sarah MM Tong, RCAT, Conference Co-chair, President of the Hong Kong Association of Art Therapists.

\section{Reference}

HKAAT - Hong Kong Association of Art Therapists, website: www.hkaat.com 